\title{
FRAGMENTATION AND RODDING IN OSTEOGENESIS IMPERFECTA
}

\author{
Peter F. Williams, Melbourne, Australia \\ From the Royal Children's Hospital, Melbourne
}

Osteogenesis imperfecta was described 250 years ago by Amand (1716) in Germany and since that time a voluminous literature has accumulated. One hundred and twenty years later the histology was studied in Von Recklinghausen's laboratory (Stilling 1889) but despite a lot of subsequent research little further is known either of the etiology or of any treatment favourably affecting the course of the disease.

Clinically the condition is characterised by dwarfism, bone fragility, ligamentous laxity, and muscle atrophy and hypotonia. Deformities occur in the long bones not only from repeated fractures with malunion and shortening, but also because the bones gradually bend into bizarre shapes without fracture. Figure 1 shows a typical deformity of the tibia in a boy of seven. He had had twenty-five fractures of various bones and had never walked.

These children have a characteristic facial appearance. The face is triangular in shape with bitemporal protuberances and a prominent frontal bone. The chest is deformed to a varying degree, with marked prominence of the sternum (Fig. 19).

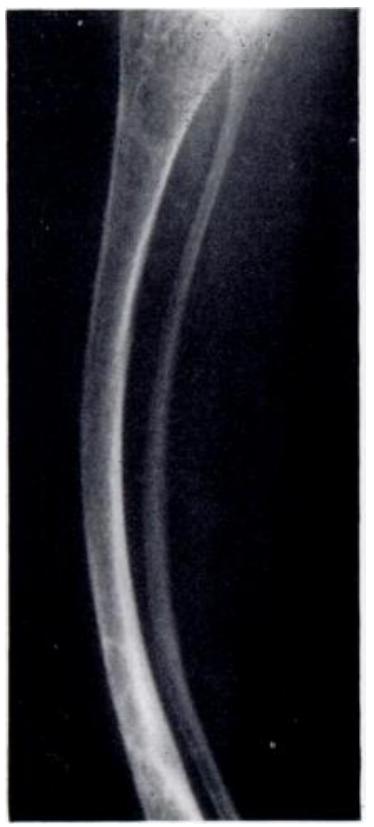

FIG. 1

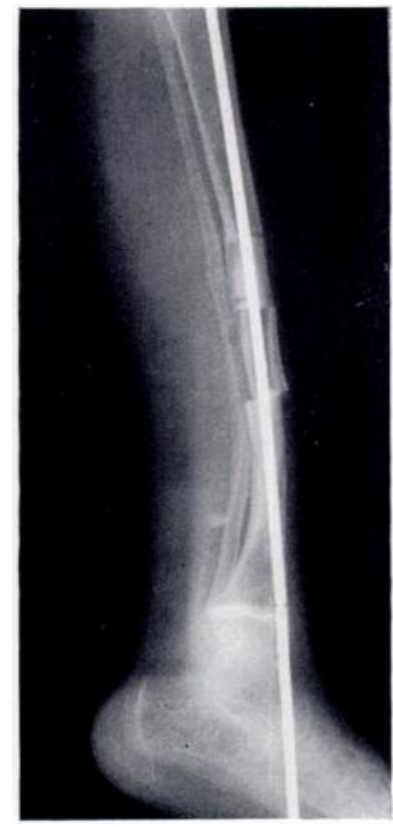

FIG. 2

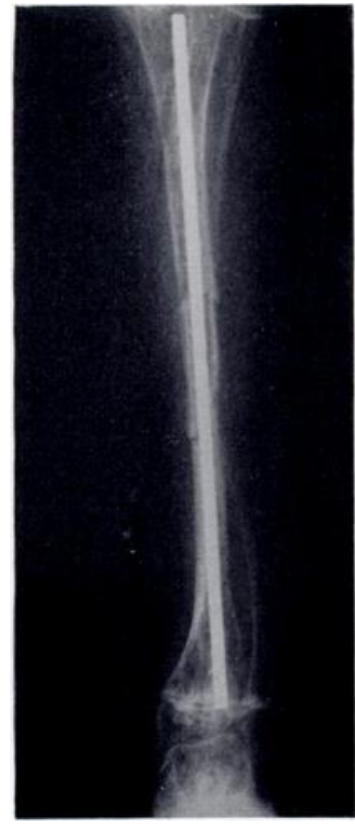

FIG. 3

Figure 1-The typical deformity in the tibia in a boy of 7 years. Figure $2-$ The joined rods having been inserted through the distal tibial fragment to emerge from the sole, were then threaded up the tibial fragments to the proximal epiphysis. The junction of the two rods is clearly shown. Figure 3-The final result after fragmentation and rodding.

Treatment of the fractures and deformities has, in the past, been conducted along accepted orthopaedic lines. In 1951 Sofield demonstrated a method of fragmentation and rodding which has revolutionised the management (Sofield, Page and Mead 1952), and Sofield and Millar described their results in 1959. This paper sets out our experience with this method at the Royal Children's Hospital in Melbourne over the last four years. A modification of the original technique for the insertion of the rods has been developed and is thought to offer

VOL. 47 B, NO. 1, FEBRUARY 1965 
many advantages. Fifty operations have been performed in eleven patients aged from ten months to eighteen years.

Equipment-Certain special instruments are required and it is essential to be fully equipped before embarking on this type of surgery. The rods are of 18/8 S.Mo. stainless steel. Four diameters are needed (one-eighth, five thirty-seconds, three-sixteenths and seven thirty-seconds of an inch respectively). These rods are made up in pairs threaded together in the centre to make a total length of two to three feet, depending on the diameter. Kirschner wires, one and two millimetres in diameter, are also needed in children under two years of age.

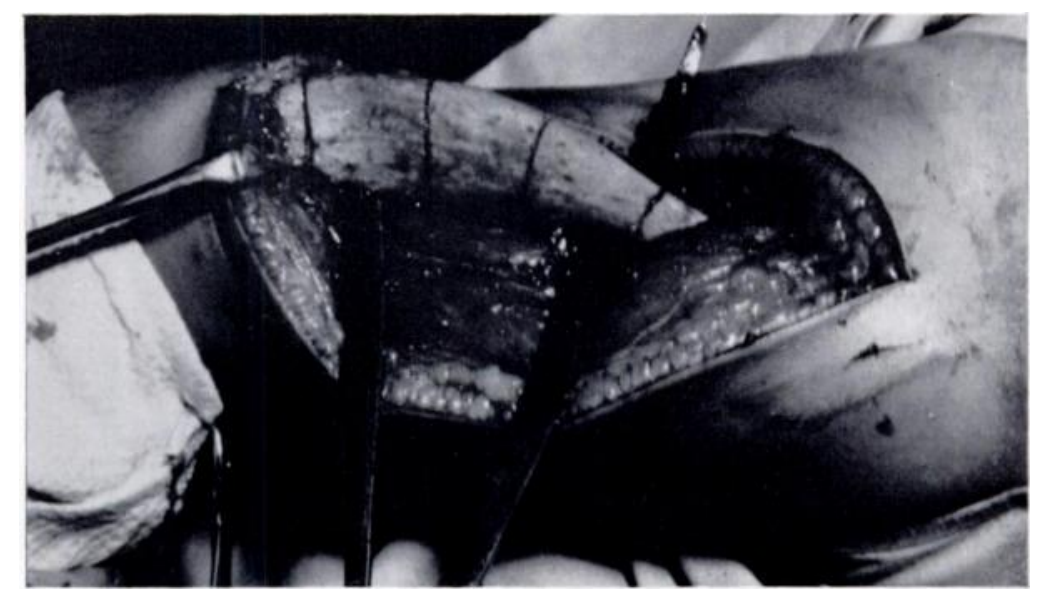

FIG. 4

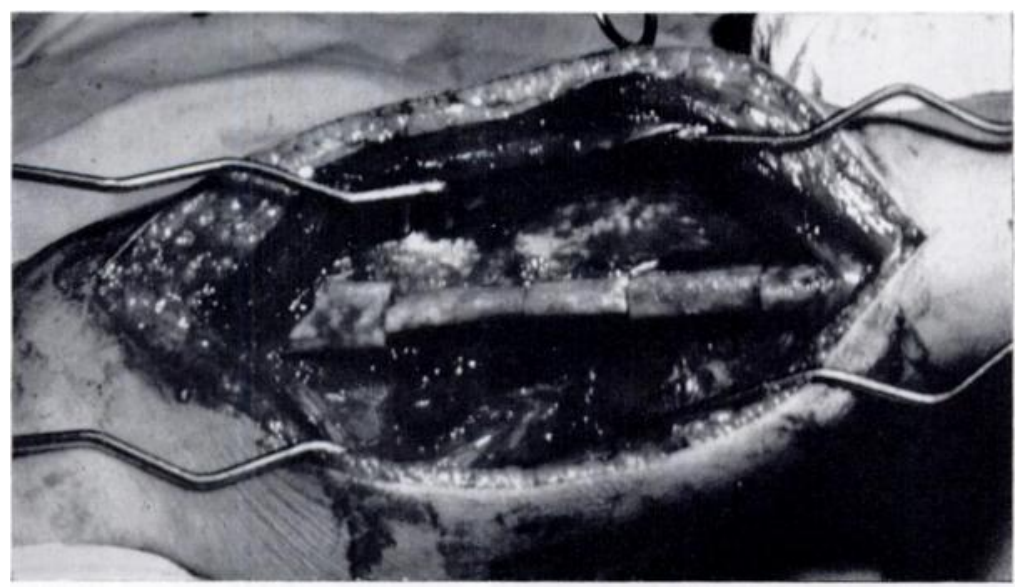

Fig. 5

Figure 4-Four osteotomies have been done in the femur. The segments will now be removed and the medullary cavity drilled out. Figure 5-After insertion of the rod the shaft is straight.

A set of drills six inches long corresponding to the size of the rods is essential. Other necessary items are benders or strong pliers to make a hooked end on the femoral rods, and a large pair of industrial bolt cutters, powerful enough to cut quarter-inch stainless steel rod.

\section{TECHNIQUE OF OPERATION}

The operation entails subperiosteal exposure of the entire shaft of the bone. It is important to emphasise that the whole shaft must be exposed because, even if the radiographs suggest 
that long lengths of the shaft are straight, this is seldom found to be so and it is better to err on the side of too many osteotomies than too few.

Except in the tibia, standard anatomical approaches are not feasible and experience has shown that it is better to incise directly down to the bone where it is nearest to the surface.

Once exposed, the shaft is cut with an oscillating motor saw into as many pieces as are necessary to achieve correction. Each fragment must be short enough to be straight. Using the narrowest fragment as a guide, a drill of suitable diameter is selected and each end of the shaft is drilled out for a short distance, taking care not to enter the epiphysial plate. Next, each of the fragments, which are often rib-shaped in section and have little or no medullary cavity, must be drilled out in turn. At all times it is necessary to exercise gentleness, because the bones are easily crushed by bone-holding forceps; the drills also tend to wander in a most erratic manner.
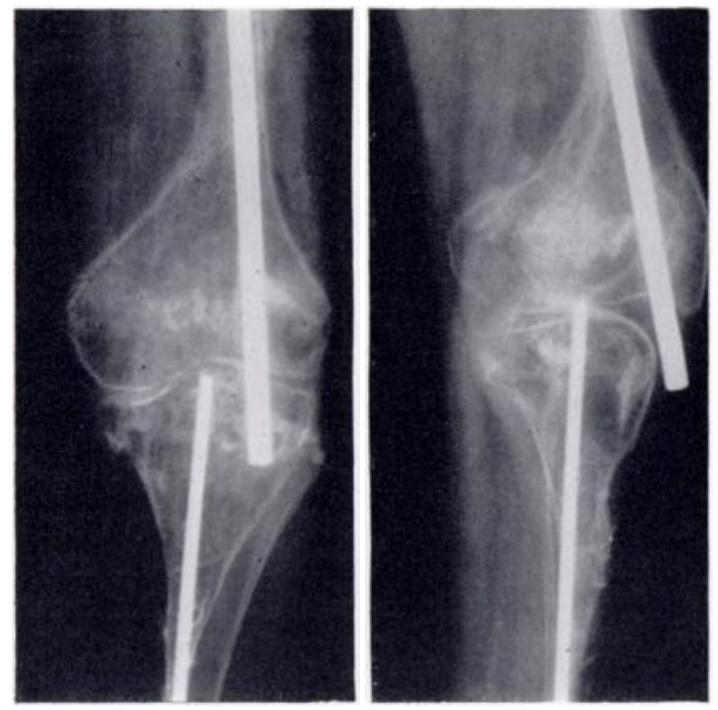

FIG. 6

FIGS. 6 AND 7

Figure 6-There has been longitudinal migration of a rod through the knee joint. Figure 7-There has been a lateral migration of the rod in the femur one year after insertion.
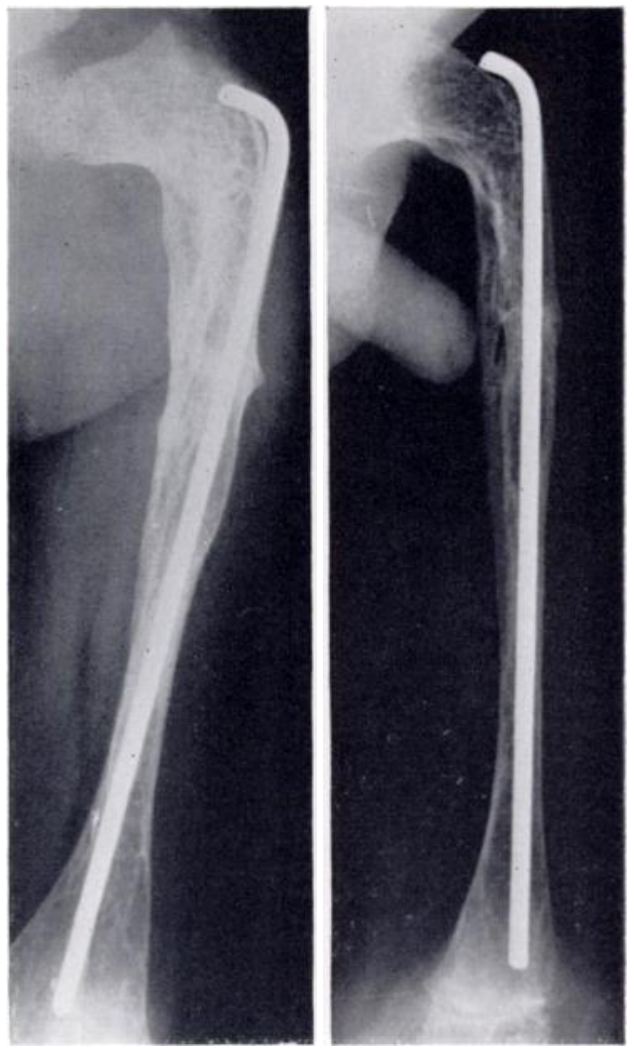

FIG. 7

The length of the rod is determined by the addition of three measurements. The first is the length of the gap between the two ends of the shaft with traction applied to the foot. Usually this is less than the total length of the fragments removed so that one of them may have to be shortened. The second and third measurements are obtained by pushing a rod into the open ends of the shaft until the resistance of the epiphysial plate is felt. For the tibia, a rod with a female thread is then cut to length and a piece of rod with a male thread screwed into it. The male end of the combined rods is then introduced into the open distal end of the shaft and pushed through to emerge from the sole of the foot. The cut fragments of the central shaft are threaded on to the rod which is pushed up until it is engaged in the proximal end of the shaft, and a radiograph is taken. The unwanted distal part of the rod is then 
unscrewed and withdrawn. In order that the rod junction may be visible it is advisable to unscrew the distal rod one turn before taking the radiograph (Figs. 2 and 3 ).

In the femur the technique is similar to that usually employed for Küntscher nailing of fractures. However, because a hook must be bent into the proximal end and because this is difficult with the rod in situ, the mated rods can again be used to simplify this. A rod of suitable diameter and length is bent on the bench and led into the proximal end by a male-ended rod introduced from below. Once the junction appears in the wound the guide rod can be removed and discarded. Figures 4 and 5 illustrate the stages in a typical case.

\section{COMPLICATIONS}

Complications in this series were few and of little importance. Despite the wide exposure and dissection all wounds healed by first intention and no sepsis occurred.

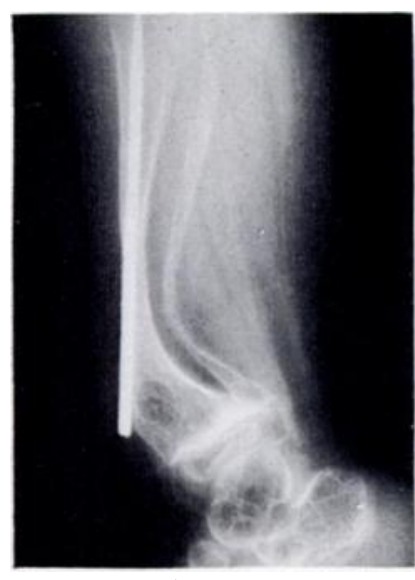

Fig. 8

Figure 8-The effect of continued growth. Gradual bending of the bone around the end of the rod is eventually followed by fracture. Figure 9-The diaphysis was replaced by the maternal fibula. This radiograph taken three months after operation shows that union is occurring.

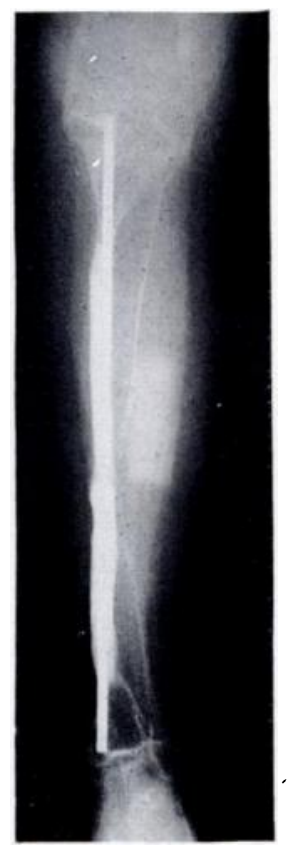

FIG. 9

Non-union-This occurred in one femur at the site of an old pseudarthrosis. It proved to be painless and in no way interfered with function (Case 1, Fig. 11).

Delayed union-An osteotomy site in the tibia of an eighteen-year-old girl, in whom the bone ends were of marble hardness and devoid of a medullary cavity, had delay in union for four months. All the other osteotomies united firmly in ten to twelve weeks.

Migration of nails-This may occur longitudinally (Fig. 6) or sideways (Fig. 7), and may necessitate replacement of the rod if the joint is penetrated. In the femur migration distally can be prevented by making a hook at the proximal end of the rod, but no method of prevention in the tibia has yet been devised. The latter complication occurred twice in the series.

Growth-Increase in length of the bones is usually shown by a gradual bending below the distal end of the rod (Fig. 8). After about two years, or if refracture occurs at this site, a longer rod should be inserted. This is simple and merely requires exposure of the distal end of the shaft at the site of the bend.

Extreme fragility - Rarely the bone is so fragile that rodding is impossible. In one patient the shaft was resected and replaced by the maternal fibula (Fig. 9). Union occurred quickly and a year later the graft was beginning to assume the radiological characteristics of the replaced tibia.

\section{CASE REPORTS}

The following case reports and illustrations are included to give a better understanding of the problems involved and the results obtained in the individual patient.

Case 1-This boy was first seen at the age of seven with a history of multiple fractures since birth. He had never walked and was severely dwarfed and deformed. A radiograph of the lower limbs showed many old and new fractures with non-union in the right femur and left 


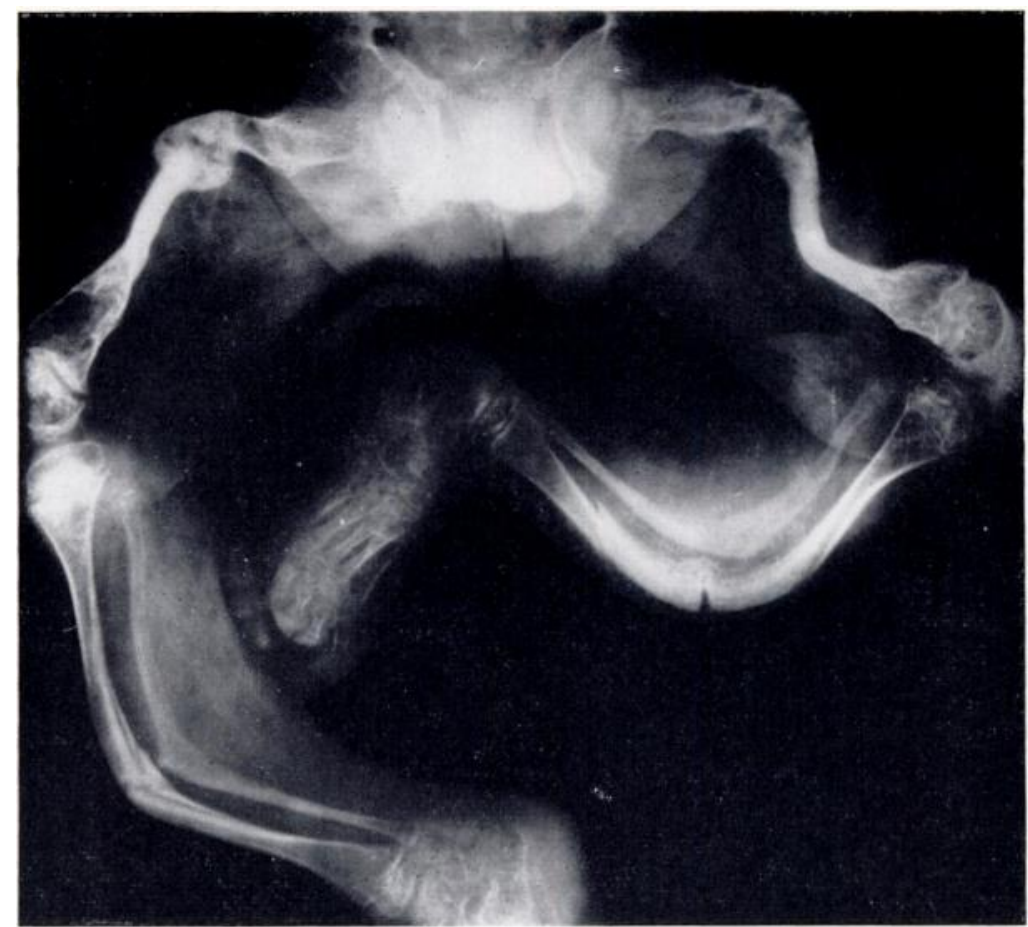

FIG. 10

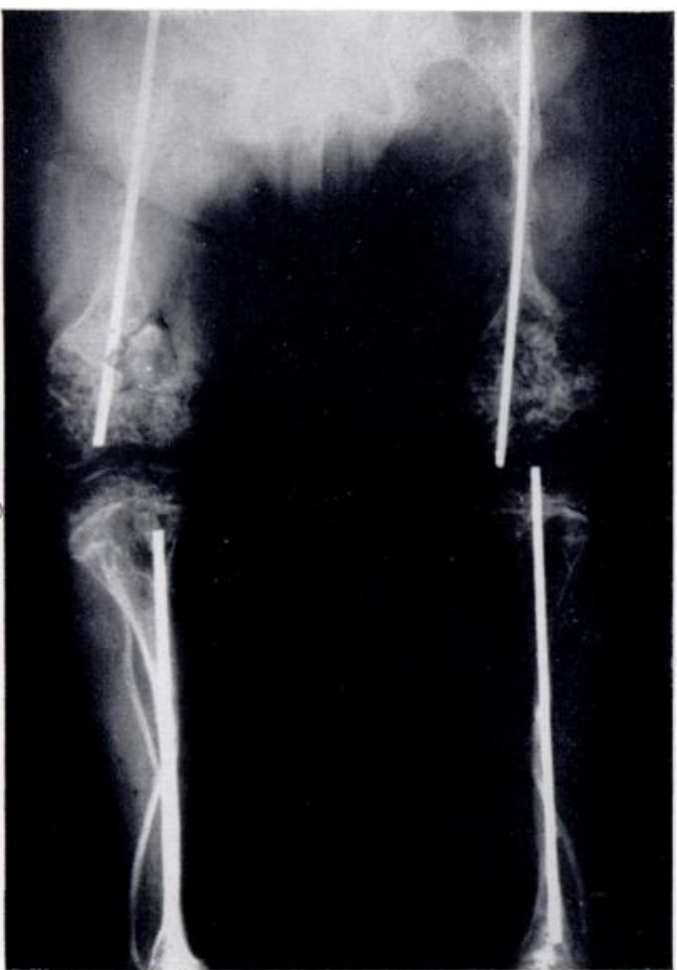

FIG. 11

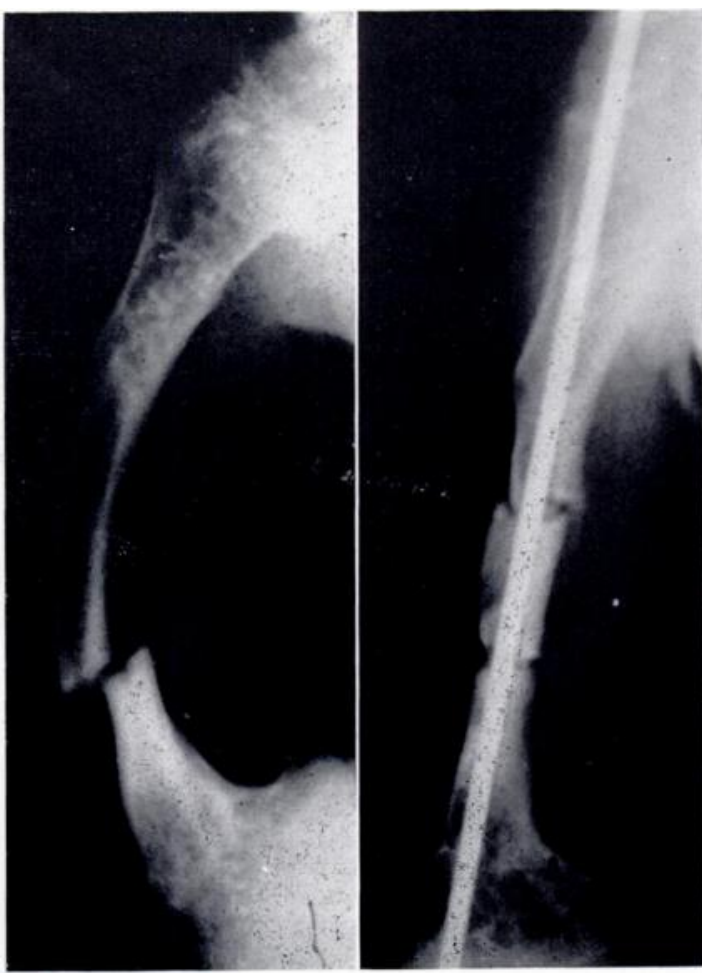

FIG. 12

Case 1. Figure 10-The radiograph of a boy aged 7 years showing many new and old fractures. There is non-union in the right femur and left tibia. Figure 11-After rodding there is still non-union in the right femur. Migration of the left femoral rod occurred and it was replaced. Figure 12-Before and after rodding of the left humerus.

VOL. 47 B, NO. 1, FEBRUARY 1965 


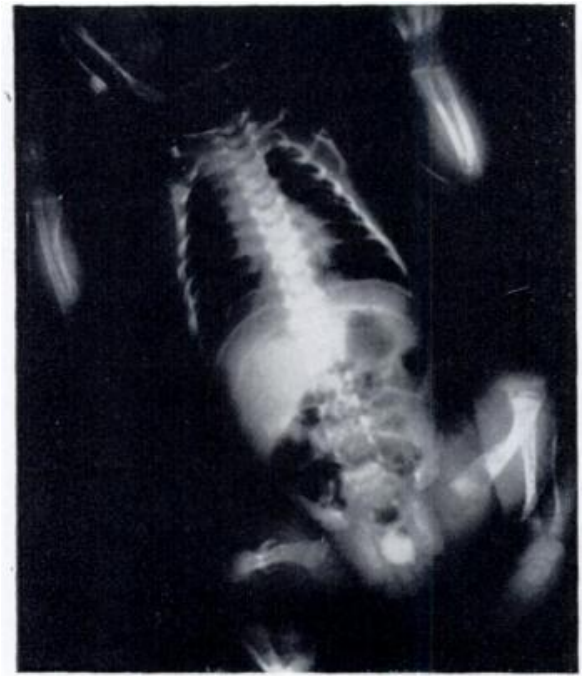

FIG. 13

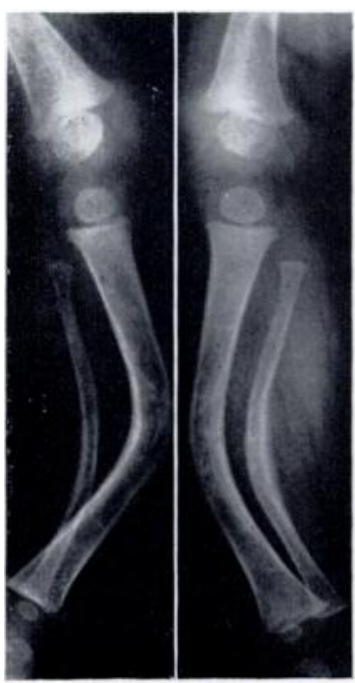

FIG. 14

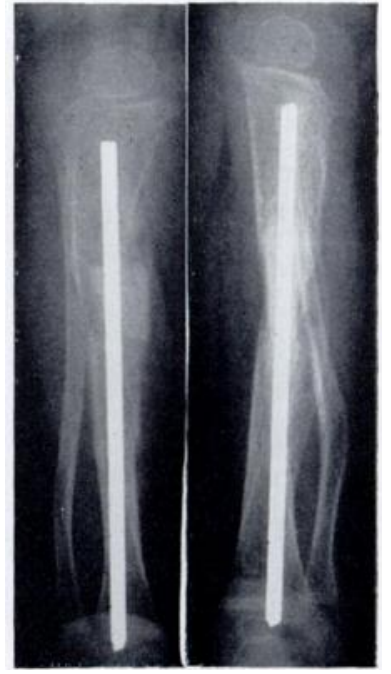

FIG. 15

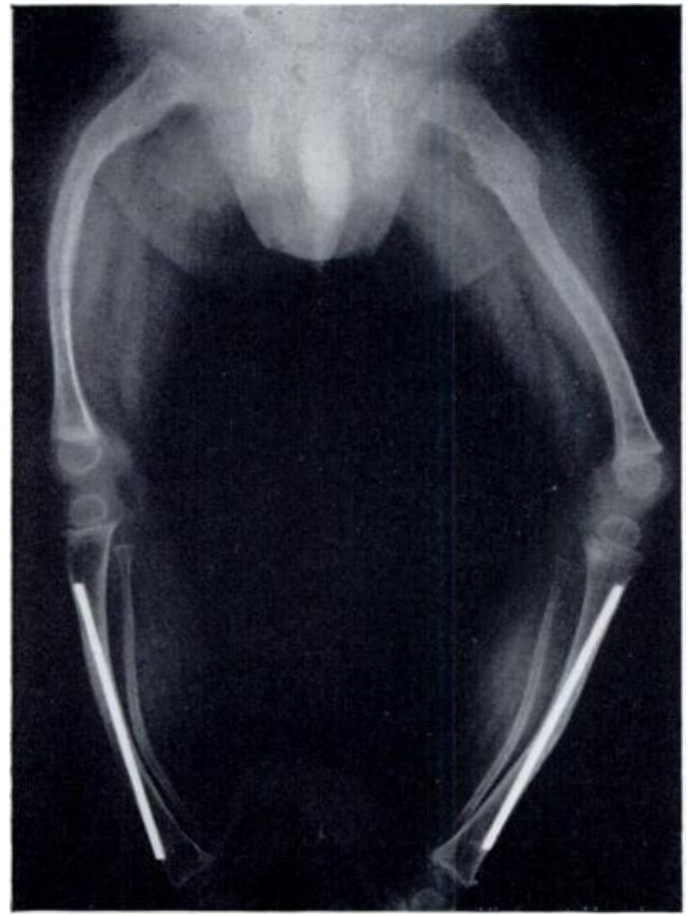

Fig. 16

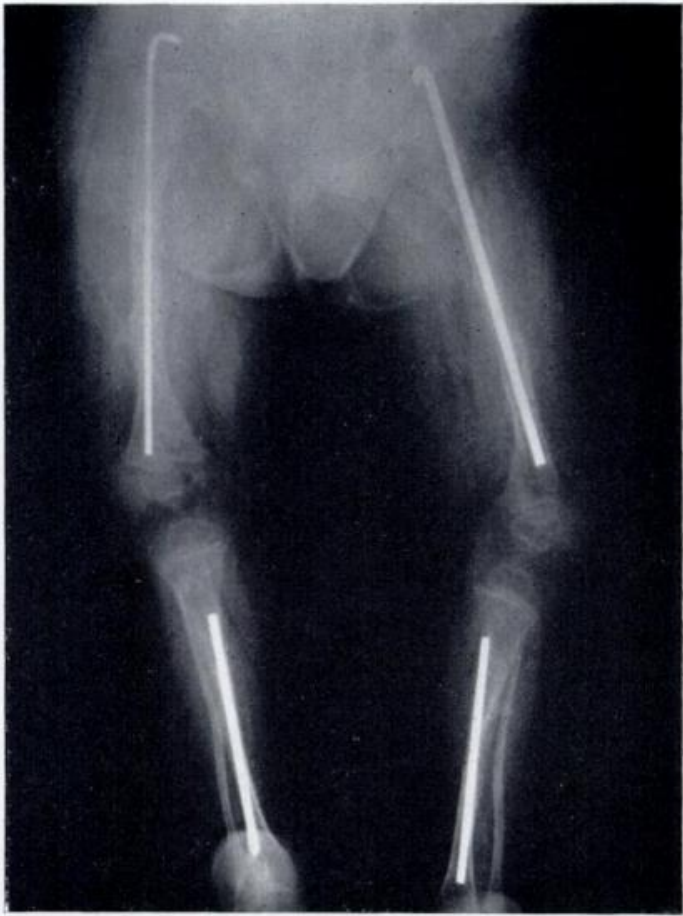

Fig. 17

Case 2. Figure 13-A radiograph at age of 5 days shows the multiple fractures. Figure 14-The tibial deformities at age of 10 months. Figure 15-After the tibiae had been rodded with Kirschner wires.

Figure 16-The femora and tibiae at the age of 21 months. Figure 17-Three months after rodding of the femora. Note that the tibial rods have already become too short. 


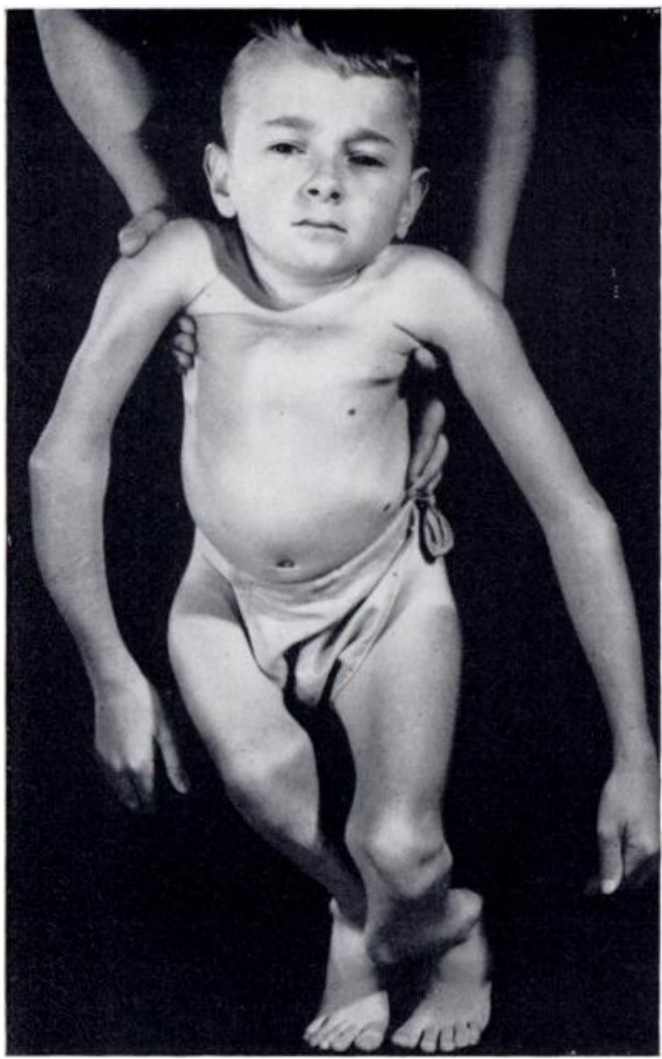

FIG. 18

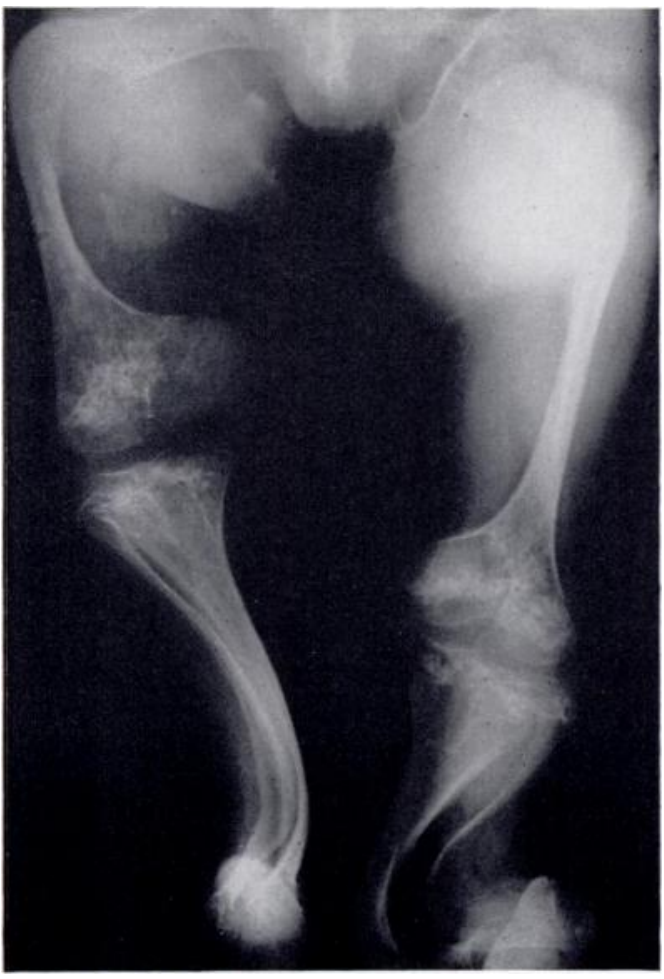

FIG. 20

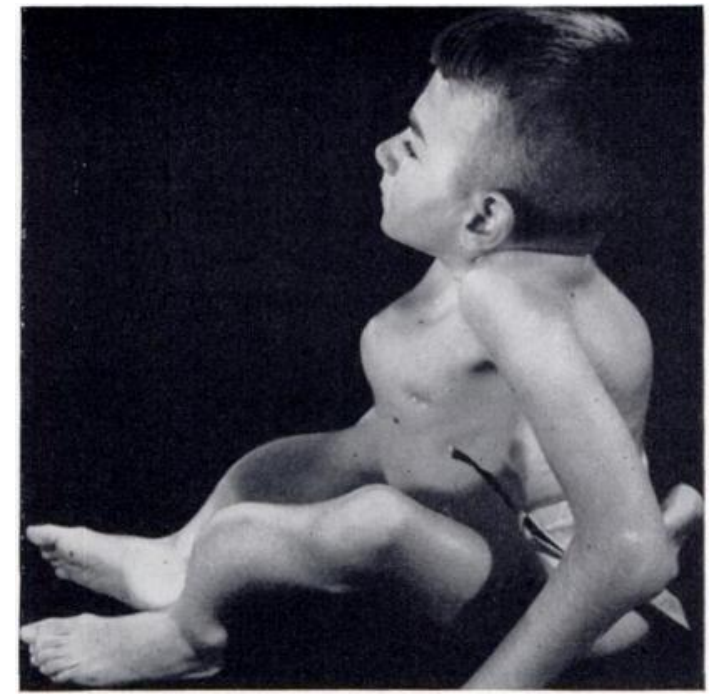

FiG. 19

FiGs, 18 To 21

Case 3. Figures 18 and 19-Clinical appearance of a boy aged 13 years before treatment. Figure 20Radiograph of the lower limbs before treatment. Figure 21 - Radiograph after fragmentation and rodding.

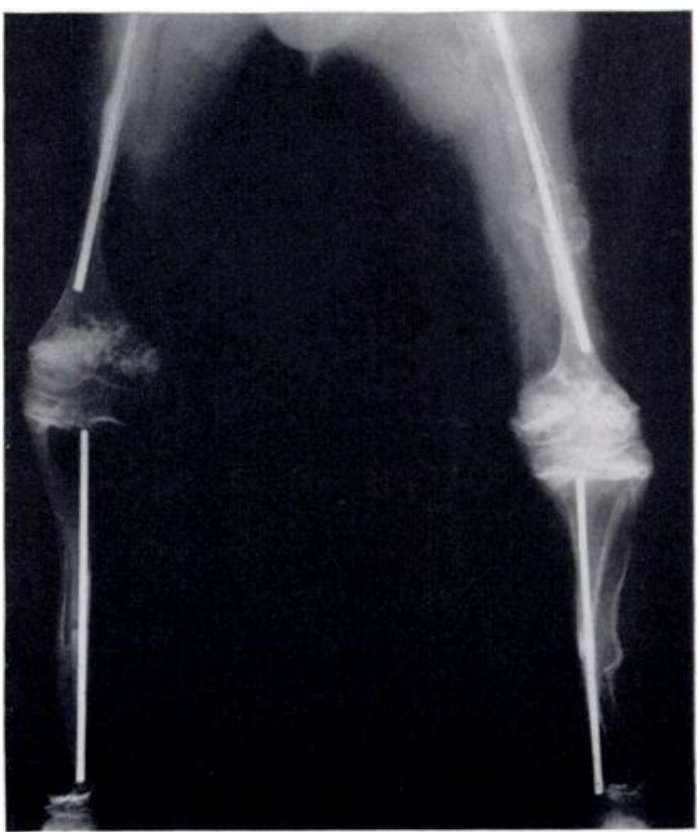

FIG. 21

VOL. 47 B, NO. 1, FEBRUARY 1965 
tibia (Fig. 10). Three years later each long bone was rodded at intervals of about one month and the child started to walk in calipers nine months later. Although non-union persisted in the right femur and the rod in the left femur migrated into the knee and had to be shortened, he has continued independent walking ever since (Fig. 11). Three years later the patient requested rodding of the left humerus after a fracture and this was carried out satisfactorily (Fig. 12).

Case 2-This boy was first seen five days after birth with fractures of both tibiae, both femora and the right humerus and radius (Fig. 13). The fractures were treated conservatively and the child thrived. At ten months gradual bending

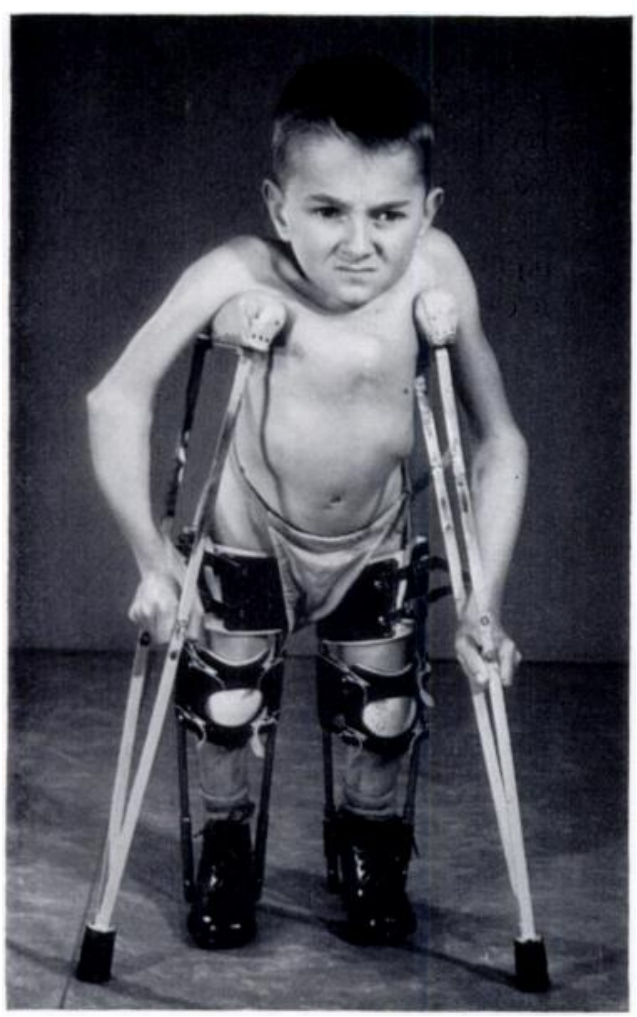

FiG. 22

Case 3-The clinical appearance after rodding. had produced the deformity seen in Figure 14 and the tibiae were fragmented and rodded, using heavy Kirschner wires (Fig. 15). At the age of twenty-one months considerable deformation of both femora was present (Fig. 16) and these were therefore rodded (Fig. 17). He started walking in calipers at the age of two and has progressed well.

Case 3-This boy, seen at the age of thirteen years, had never walked and presented with severe deformities of the trunk and lower limbs (Figs. 18 to 20). At fortnightly intervals fragmentations and roddings were carried out uneventfully. Plaster immobilisation was used after each operation, so that finally the boy was in a double hip spica. This was removed six months after the first operation and calipers were fitted. After only three days' instruction the boy was able to walk alone, with the aid of crutches, and continued to make good progress thereafter. Figures 21 and 22 show the final result.

\section{DISCUSSION}

Our experience has shown beyond doubt that the operation of fragmentation and rodding in osteogenesis imperfecta is sound and offers the patient a new life, which is virtually free

of fractures. The only difficult question to answer is at what age should rodding start? If the child is approaching maturity when first seen there is obviously no need to delay operation; but when the child is presented at a very early age there may be considerable discussion as to the best time to operate. The youngest patient in this series was ten months old. It is considered unwise to insert a rod at an earlier age. After two years a child treated at ten months will soon be needing longer rods, because increasing deformity will be taking place with further growth. However, if rodding is delayed and progressive deformity accepted, considerable loss of length is inevitable, because the bone at the apex of the curve has to be discarded at operation to compensate for the soft-tissue contractures. Because all the children with osteogenesis imperfecta are severely dwarfed, any further loss in height is undesirable. When all these factors are considered it seems desirable to insert rods as soon as deformity starts to appear, though it must be realised that re-operation will almost certainly be required every three years. 


\section{SUMMARY}

1. Fifty operations of fragmentation and rodding in the long bones of patients with osteogenesis imperfecta are reported.

2. The technique of the operation is described and a modification of Sofield's original method is suggested.

3. The results and complications of treatment are described.

\section{REFERENCES}

Amand, P. (1716), cited by A. Dietrich: In Handbuch der speziellen pathologischen Anatomie und Histologie. 1929. Band 9, Erster Teil, Seite 194. Berlin: Julius Springer.

Sofield, H. A., and Millar, E. A. (1959): Fragmentation, Realignment, and Intramedullary Rod Fixation of Deformities of the Long Bones in Children. Journal of Bone and Joint Surgery, 41-A, 1371.

Sofield, H. A., Page, M. A., and Mead, N. C. (1952): Multiple Osteotomies and Metal-Rod Fixation for Osteogenesis Imperfecta. Journal of Bone and Joint Surgery, 34-A, 500.

Stilling, H. (1889): Osteogenesis imperfecta. Virchow's Archiv für pathologische Anatomie, 115, 357.

VOL. 47 B, NO. 1, FEBRUARY 1965 